\title{
Viscosity and Ionic Conductivity of Imidazolium based Ionic Liquids bearing Triiodide Anion
}

\author{
Ruwaida Asyikin Abu Talip ${ }^{1}$, Wan Zaireen Nisa Yahya ${ }^{1,2}$ * and Mohamad Azmi Bustam ${ }^{1,2}$ \\ ${ }^{1}$ Chemical Engineering Department, Universiti Teknologi PETRONAS, 32610 Seri Iskandar, Perak, Malaysia \\ ${ }^{2}$ Centre of Research in Ionic Liquids, Universiti Teknologi PETRONAS, 32610 Seri Iskandar, Perak, Malaysia
}

\begin{abstract}
In the electrolyte application for dye sensitized solar cells, utilization of ionic liquids is getting the highlights to replace volatile organic solvent thanks to their low volatility, thermal and electrochemical stability. The iodide/triiodide redox electrolyte is the preferred choice for this application, hence numerous iodide-based ionic liquids have been explored and reported. On the contrary, the transport properties of triiodide based ionic liquid is often lack of reporting despite of having an equal influence on the overall viscosity and ionic conductivity of the electrolyte. In this study, three alkylimidazolium triiodide ionic liquids were synthesized from the respective alkylimidazolium iodide ionic liquids precursors and their physicochemical and conductivity properties are reported. ${ }^{1} \mathrm{H}$ NMR analysis showed a slight shifting of position of the resonances of triiodide based alkylimidazolium ionic liquids as compared to their precursors due to less electronegativity nature of triiodide anion. The formation of triiodide-based imidazolium ILs have dramatically altered the transport properties in which the ionic liquids obtained are of low viscosity and high ionic conductivity.
\end{abstract}

\section{Introduction}

Ionic liquids (ILs) have emerged as an ideal material in various energy application such as capacitors, dye sensitized solar cells (DSSC), batteries and other electrochemical applications [1]. The properties of ILs that have negligible vapor pressure, high thermal stability, non-flammability and have wide electrochemical window make them suitable to replace conventional electrolytes [2]. The incorporation of ILs as part of electrolyte in DSSC is not new especially imidazolium iodide based ionic liquids. The selection criteria of ILs for the electrolyte application needs to take into consideration the transport properties such as viscosity and ionic conductivity of the ILs as they affect the overall performance of the cell. The commonly used IL for DSSC notably 1-propyl-3-methyl-imidazolium iodide (PMII) is often added as additive to enhance ionic conductivity [3-5]. Besides that, iodide-based ionic liquids also play the role as one of the redox couples that aid in the dye regeneration [6].

Almost systematically in DSSC electrolyte, iodine is added to iodide based ILs to become the iodide/triiodide redox couple. This combination of iodide/triidode based ILs are considered as favourite and classical choice as redox electrolyte as it is by far stay the most stable combination with high power conversion efficiency [7]. However only iodide-based ionic liquids are vastly reported of their transport properties. For instance, properties such as viscosity and ionic conductivity of 1propyl-3-methylimidazolium iodide and 1-butyl-3methylimidazolium iodide are extensively reported [8,
9]. On the contrary, the triiodide-based ionic liquids are often lack of reporting despite of having an equal influence on the overall viscosity and ionic conductivity of the electrolyte. Thus, it is of paramount importance to characterize triiodide based ILs on their own. Not limited for the application in DSSC only, these fundamental data of triiodide based ILs might shed a new perspective in term of incorporating these materials into different application in the future.

In this recent study, three alkylimidazolium iodide ILs of different alkyl chain length (C3-C5) were synthesized to be the precursor to obtain three imidazolium triiodide ILs. The synthesized ILs were characterized using proton nuclear magnetic resonance ( ${ }^{1} \mathrm{H}$ NMR) followed by the exploration on the transport properties such as viscosity and ionic conductivity. Apart from physical alteration, the formation of triiodide based ILs will influence the transport properties of the ILs. This study is hoped to shed light on the suitability of triiodide based ILs to be incorporated into different energy application.

\section{Experimental method}

\subsection{Materials}

1-methylimidazolium (purity of 99\%), propyl iodide (purity of 98\%), butyl iodide (purity of $98 \%$ ), pentyl iodide (purity of $98 \%$ ), solid iodine (purity of $99.8 \%$ ), tetrahydrofuran (THF), cyclohexane, methanol and ethyl

\footnotetext{
* Corresponding author: zaireen.yahya@utp.edu.my
} 
acetate were purchased from Sigma-Aldrich and used without further purification.

\subsection{Characterization method}

The ${ }^{1} \mathrm{H}$ NMR spectra were recorded using $500 \mathrm{MHz}$ of Bruker Ascend 500 using DMSO-d6 as solvent and tetramethylsilane (TMS) as internal standard. The viscosity were determined using Anton Paar Viscometer SVM 3000. The conductivity of the ILs were determined using Wonatech, WEIS10 Electrochemical Impedance Spectrometer. The alternate current (AC) impedance method was used with amplitude of $10 \mathrm{mV}$ in the range of $0.1 \mathrm{~Hz}$ to $10^{3} \mathrm{~Hz}$ at $298 \mathrm{~K}$ where sample was placed in between two stainless steel electrodes. The obtained spectra were fitted using Autolab NOVA 1.10 using Randles equivalent circuit where the ohmic resistance of the electrolyte $(\mathrm{R})$ was obtained and use to calculate conductivity $(\sigma)$ in S. $\mathrm{m}^{-1}$ using the Equation (1):

$$
\sigma=l / \mathrm{R}_{\mathrm{s}} \cdot \mathrm{S}
$$

Where $l$ is the distance of the two electrodes in meter, $\mathrm{R}_{\mathrm{S}}$ is the solution ohmic resistance $(\Omega)$ and $\mathrm{S}$ is the surface area of the electrode in meter ${ }^{2}$.

\subsection{Synthesis of iodide and triiodide based ionic liquids (ILs)}

\subsubsection{Synthesis of 1-alkyl-3-methylimidazolium iodide}

The synthesis procedures for the ILs were adapted from Zhang et al. [4] with slight modification. Colorless solution of 0.25 mole alkyl iodide was added dropwise into a round bottom flask containing an equimolar amount of colorless 1-methylimidazolium solution in 20 $\mathrm{ml}$ of acetonitrile. The colorless mixture was stirred at room temperature for 18 hours. The resulting paleyellow solution was washed using THF and ethyl acetate. The extract layer was concentrated using rotary evaporator at reduced pressure for 16 hours to obtain the iodide ILs.

1-propyl-3-methylimidazolium iodide, [PMIM][I]: Yield (57.03 g, 90.00\% yield). ${ }^{1} \mathrm{H}$ NMR (500 MHz, DMSO-d6: $\delta \mathrm{ppm}=9.19(1 \mathrm{H}, \mathrm{s}), 7.81(1 \mathrm{H}, \mathrm{s}), 7.74(1 \mathrm{H}$, s), 4.16-4.13 (2H, t), $3.86(3 \mathrm{H}, \mathrm{s}), 1.81-1.74(2 \mathrm{H}, \mathrm{m})$, 0.82-0.79 (3H, t)).

1-butyl-3-methylimidazolium iodide, [BMIM][I]: Yield (58.56 g, 88.02 \%). ${ }^{1} \mathrm{H}$ NMR (500 MHz, DMSO-d6: $\delta$ $\mathrm{ppm}=9.18(1 \mathrm{H}, \mathrm{s}), 7.81(1 \mathrm{H}, \mathrm{s}), 7.74(1 \mathrm{H}, \mathrm{s}), 4.21-4.18$ $(2 \mathrm{H}, \mathrm{t}), 3.87(3 \mathrm{H}, \mathrm{s}), 1.81-1.75(2 \mathrm{H}, \mathrm{t}), 1.30-1.23(2 \mathrm{H}$, m), 0.92-0.89 (3H, m)). 1-pentyl-3-methylimidazolium iodide, [PENMIM][I]: Yield (31.27 g, 89.30 \%). ' H NMR (500 MHz, DMSO$d 6: \delta \mathrm{ppm}=9.19(1 \mathrm{H}, \mathrm{s}), 7.81(1 \mathrm{H}, \mathrm{s}), 7.73(1 \mathrm{H}, \mathrm{s})$, 4.18-4.16 (2H, t), $3.86(3 \mathrm{H}, \mathrm{s}), 1.79-1.76(2 \mathrm{H}, \mathrm{t}), 1.30-$ $1.26(2 \mathrm{H}, \mathrm{m}), 1.22-1.189(2 \mathrm{H}, \mathrm{m}), 0.85-0.82(3 \mathrm{H}, \mathrm{m}))$.

\subsubsection{Synthesis of 1-alkyl-3-methylimidazolium triiodide}

A $20 \mathrm{ml}$ of pale-yellow acetonitrile solution of $0.05 \mathrm{~mol}$ of 1-alkyl-3-methylimidazolium iodide in a round bottom flask was added with 0.05 mol of solid iodine. The dark brown resulting mixture was stirred at room temperature in inert condition for 48 hours. The resulting thick brown liquid was subjected to extraction using cyclohexane and methanol. The extract layer was then concentrated using rotary evaporator at reduced pressure for 16 hours to obtain the triiodide ILs.

1-propyl-3-methylimidazolium triiodide, [PMIM][ $\left[\mathrm{I}_{3}\right]$ : Yield (25.10 g, $98.00 \%) .{ }^{1} \mathrm{H}$ NMR (500 MHz, DMSO$d 6: \delta \mathrm{ppm}=9.09(1 \mathrm{H}, \mathrm{s}), 7.75(1 \mathrm{H}, \mathrm{s}), 7.69(1 \mathrm{H}, \mathrm{s}), 4.13-$ $4.11(2 \mathrm{H}, \mathrm{t}), 3.85(3 \mathrm{H}, \mathrm{s}), 1.84-1.77(2 \mathrm{H}, \mathrm{m}), 0.87-0.85$ $(3 \mathrm{H}, \mathrm{t}))$.

1-butyl-3-methylimidazolium triiodide, [BMIM][ $\left.\mathrm{I}_{3}\right]$ : Yield (25.03 g, $96.30 \%$ ). ${ }^{1} \mathrm{H}$ NMR (500 MHz, DMSO$d 6: \delta \mathrm{ppm}=9.10(1 \mathrm{H}, \mathrm{s}), 7.76(1 \mathrm{H}, \mathrm{s}), 7.76(1 \mathrm{H}, \mathrm{s})$, 4.17-4.14 (2H, t), $3.85(3 \mathrm{H}, \mathrm{s}), 1.78-1.75(2 \mathrm{H}, \mathrm{t}), 1.28-$ $1.24(2 \mathrm{H}, \mathrm{m}), 0.92-0.89(3 \mathrm{H}, \mathrm{m}))$.

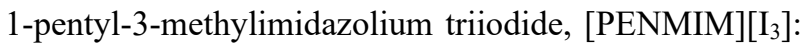
Yield (26.64g, 96.78 \%). ${ }^{1} \mathrm{H}$ NMR (500 MHz, DMSO$d 6: \delta \mathrm{ppm}=9.09(1 \mathrm{H}, \mathrm{s}), 7.76(1 \mathrm{H}, \mathrm{s}), 7.69(1 \mathrm{H}, \mathrm{s})$, 4.16-4.13 (2H, t), $3.84(3 \mathrm{H}, \mathrm{s}), 1.81-1.75(2 \mathrm{H}, \mathrm{t}), 1.35-$ $1.28(2 \mathrm{H}, \mathrm{m}), 1.25-1.21(2 \mathrm{H}, \mathrm{m}), 0.88-0.87(3 \mathrm{H}, \mathrm{m}))$.

\section{Results and Discussion}

The iodide based ionic liquids namely [PMIM][I], $[\mathrm{BMIM}][\mathrm{I}]$ and $[\mathrm{PENMIM}][\mathrm{I}]$ were synthesized in the first place to act as the precursors to obtain [PMIM] $\left[\mathrm{I}_{3}\right]$, $[\mathrm{BMIM}]\left[\mathrm{I}_{3}\right]$ and $[\mathrm{PENMIM}]\left[\mathrm{I}_{3}\right]$ respectively. The alkylimidazolium iodide ionic liquids [PMIM][I], $[\mathrm{BMIM}][\mathrm{I}]$ and $[\mathrm{PENMIM}][\mathrm{I}]$ obtained were all in viscous yellow liquids. Each of these three imidazolium iodide ILs were then reacted with an equimolar amount of iodine to yield $[\mathrm{PMIM}]\left[\mathrm{I}_{3}\right], \quad[\mathrm{BMIM}]\left[\mathrm{I}_{3}\right]$ and $[\mathrm{PENMIM}]\left[\mathrm{I}_{3}\right]$ which are all in the form of black liquid. The iodide and triiodide based ILs were obtained in the percentage yield of $88-90 \%$ and $96-98 \%$ respectively.

\section{1 ${ }^{1}$ NMR Spectroscopy}

The synthesized ionic liquids were analyzed using ${ }^{1} \mathrm{H}$ NMR spectroscopy which further confirmed the structure and purity of all synthesized ILs. As observed in Figure 1, the formation of triiodide based ILs from 
iodide based ILs causes a variation in the position of the resonances. As both $[\mathrm{PMIM}][\mathrm{I}]$ and $[\mathrm{PMIM}]\left[\mathrm{I}_{3}\right]$ bear the same cations, the integration of the protons in both spectra is the same except that some of the signals are shifted slightly towards upfield area. The singlets at 9.19 (a'), 7.81 (b') and 7.74 (c') ppm attributed to the aromatic protons of the imidazolium moiety of [PMIM][I] shifted upfield to 9.09 (a), 7.75 (b) and 7.69 (c) respectively for $[\mathrm{PMIM}]\left[\mathrm{I}_{3}\right]$. Proton at a, b and c are the most affected by the formation of triiodide anion due to its position as acidic protons [4].

This can be explained by the increase of the atomic radius of anion after the formation of iodide $\left(\mathrm{I}^{-}\right)$to triiodide $\left(\mathrm{I}_{3}^{-}\right)$ion hence promotes a greater charge distribution on the surface of anion $\mathrm{I}_{3}{ }^{-}$making it to be less electronegative. Thus, the coulombic interaction between the cation and the anion becomes weaker, the protons of the cation become shielded and the resonances moved slightly towards lower chemical shift [11]. The same pattern of shielding of acidic protons are also observed for resonances in spectrum of [BMIM][I3] and [PENMIM][I3] when comparing with their precursor $[\mathrm{BMIM}][\mathrm{I}]$ and [PENMIM][I] respectively.

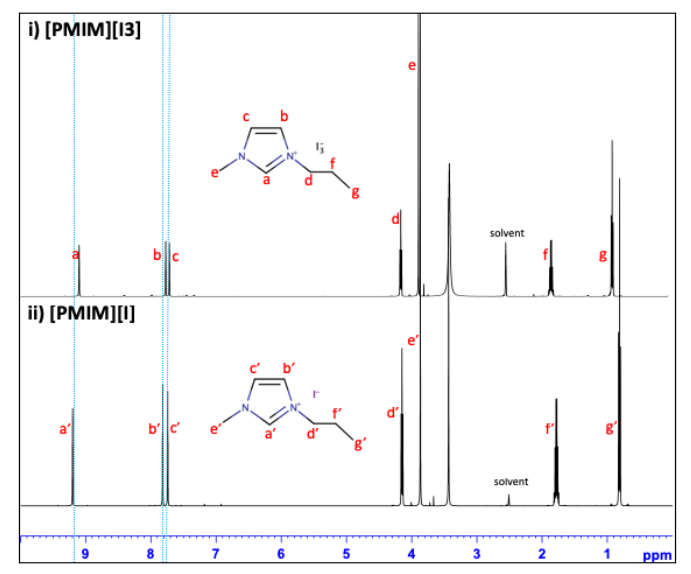

Fig. 1. ${ }^{1} \mathrm{H}$ NMR spectrum of i) $[\mathrm{PMIM}][\mathrm{I}]$ and ii) $[\mathrm{PMIM}][\mathrm{I} 3]$

\subsection{Dynamic Viscosity}

Viscosity is one of transport properties of fluid which may influence the ions transport in the electrolyte. The dynamic viscosities for iodide and triiodide based ILs in temperature range of 293 to $363 \mathrm{~K}$ are plotted in Figure 2. The viscosity is the result of momentum transfer between molecules thus it is governed by the intermolecular forces such as van der Waals attraction, hydrogen bonding, and coulombic force [12]. It can be observed that the longer the alkyl chain, the higher the viscosity as the result of higher van der Waals attraction. This is true for both iodide and triiodide based ILs though the differences of viscosity in between the triiodide based ILs of different alkyl chain is relatively quite small.

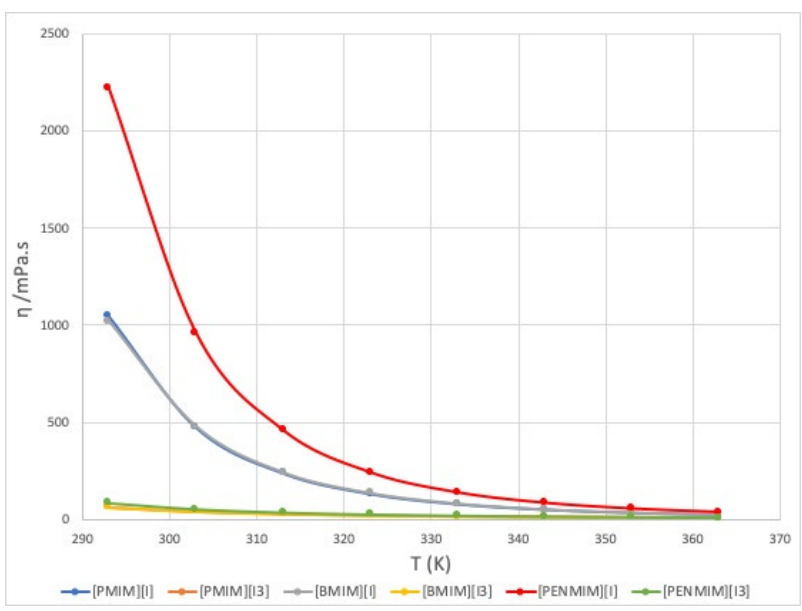

Fig. 2. Viscosity of iodide and triiodide based ILs as a function of temperature

The triiodide based ILs showed a significant decrease in viscosity difference from iodide based ILs. The formation of less electronegative triiodide anion has weakened the Coulombic attraction that holds the anion and cation together, hence, lowering the viscosity. As for the effect of temperature, it can be observed that the viscosity decreases as the temperature increases which signifies that the intermolecular forces that determine the viscosity of ionic liquid are highly affected by temperature [13].

\subsection{Ionic Conductivity}

The ionic conductivity of synthesized ILs are summarized in Table $\mathbf{1}$. Comparing the ionic conductivity in between three iodide based imidazolium ILs, [PMIM][I] gives the highest ionic conductivity, $0.169 \mathrm{~S} / \mathrm{m}$. It has also the lowest viscosity among the iodide based ILs. It is known that the higher the viscosity the lower the ionic conductivity. High viscosity environment impedes ion diffusion henceforth leading to low ionic conductivity [14]. In the case of low viscosity triiodide-based imidazolium ILs, the effect of different of length of alkyl chain on ionic conductivity is minimum compared to iodide based imidazolium ILs.

Table 1. Ohmic resistance and ionic conductivity of the synthesized ILs

\begin{tabular}{|c|c|c|}
\hline Ionic Liquids & Rs $(\Omega)$ & $\sigma(\mathbf{S} / \mathbf{m})$ \\
\hline$[\mathrm{PMIM}][\mathrm{I}]$ & 377 & 0.169 \\
\hline$[\mathrm{BMIM}][\mathrm{I}]$ & 910 & 0.070 \\
\hline$[\mathrm{PENMIM}][\mathrm{I}]$ & 1700 & 0.037 \\
\hline$[\mathrm{PMIM}]\left[\mathrm{I}_{3}\right]$ & 75 & 0.849 \\
\hline$[\mathrm{BMIM}]\left[\mathrm{I}_{3}\right]$ & 80 & 0.796 \\
\hline$[\mathrm{PENMIM}]\left[\mathrm{I}_{3}\right]$ & 112.18 & 0.567 \\
\hline
\end{tabular}


When the anion was changed from iodide to triiodide anion, a drastic increment in ionic conductivity was observed. For instance, the ionic conductivity of $[\mathrm{PENMIM}]\left[\mathrm{I}_{3}\right]$ is found to be 15 -fold greater than [PENMIM][I]. The presence of less electronegative triiodide anion has weakened the coulombic attraction in between cation and anion. This has severely impacted the transport properties of resulting ILs in which all triiodide based ILs are having low viscosity as well as high ionic conductivity. The ionic conductivity of synthesized ionic liquids in decreasing order is $[\mathrm{PMIM}]\left[\mathrm{I}_{3}\right]>[\mathrm{BMIM}]\left[\mathrm{I}_{3}\right]>[\mathrm{PENMIM}]\left[\mathrm{I}_{3}\right]>[\mathrm{PMIM}][\mathrm{I}]>$ $[\mathrm{BMIM}][\mathrm{I}]>[\mathrm{PENMIM}][\mathrm{I}]$.

\section{Conclusion}

Three iodide-based imidazolium ionic liquids namely [PMIM][I], [BMIM][I] and [PENMIM][I] were synthesized and acted as precursors to obtain three triiodide-based imidazolium ionic liquids [PMIM][ $\left.\mathrm{I}_{3}\right]$, $[\mathrm{BMIM}]\left[\mathrm{I}_{3}\right]$ and $[\mathrm{PENMIM}]\left[\mathrm{I}_{3}\right]$ respectively. Characterization of synthesized ILs using ${ }^{1} \mathrm{H}$ NMR showed that the resonances in triiodide based ILs shifted slightly upfield compared to their precursor albeit the integration of the signals are the same. This is due to the greater charge distribution on the surface of anion making it to be less electronegative. Thus, the coulombic interaction between the cation and the anion become weaker. It has drastically altered the transport properties of triiodide based ILs compared to their iodide precursor. It was found that triiodide anion has effectively resulting in a formation of ILs of low viscosity with high ionic conductivity.

The authors would like to acknowledge Chemical Engineering Department, Centre of Ionic Liquid (CORIL) for the technical and facilities support. We also acknowledge financial support from Malaysia Ministry of Education fundamental research grant (FRGS/1/2017/TK10/UTP/03/3) and YUTP-fundamental research grant $(015 \mathrm{LC} 0-080)$ for this project.

\section{References}

1. R. Lin, P.L. Taberna, S. Fantini, V. Presser, C.R. Pérez, F. Malbosc, H.L. Rupesinghe, K.B.K. Teo, Y. Gogotsi, P. Simon, J. Phys. Chem. Lett., 2, 23962401 (2011)

2. K. Sharma, V. Sharma, and S.S. Sharma, Nanoscale Res. Lett., 13, 1-46 (2018)

3. S. Kambe, S. Nakade, T. Kitamura, Y. Wada, and S. Yanagida, J. Phys. Chem. B, 106, 2967-2972 (2002)

4. W. Zhang, C. Willa, J. Sun, R. Guterman, and A. Taubert, Polymer, Polymer, 124, 246-251 (2017)

5. A. Syairah, M.H. Khanmirzaei, N.M. Saidi, N.K. Farhana, S. Ramesh, K. Ramesh and S. Ramesh, Ionics, 25, 2427-2435 (2019)

6. A. Carella, F. Borbone, and R. Centore, Front. Chem., 6, 1-24 (2018)
7. P. Wang, S.M. Zakeeruddin, P. Comte, I. Exnar, and M. Grätzel, J. Am. Chem. Soc., 125, 1166-1167 (2003)

8. M.H. Ghatee, M. Zare, F. Moosavi, and A.R. Zolghadr, J. Chem. Eng. Data, 55, 3084-3088 (2010)

9. M. Bidikoudi, L.F. Zubeir, and P. Falaras, J. Mater. Chem. A, 2, 15326-15336 (2014)

10. H. Abe, M. Aono, T. Kiyotani, and S. Tsuzuki, Phys. Chem. Chem. Phys., 18, 32337-32344 (2016)

11. T. Cremer, C. Kolbeck, K.R.J. Lovelock, N. Paape, R. Wölfel, P.S. Schulz, P. Wasserscheid, H. Weber, J. Thar, B. Kirchner, F. Maier and H.P. Steinrück Chem. - A Eur. J., 16, 9018-9033 (2010)

12. Z.K. Koi, W.Z.N. Yahya, R.A.A. Talip, and K.A. Kurnia, New J. Chem., 43, 16207-16217 (2019)

13. C.M. Roland, S. Bair and R. Casalini, J. Chem. Phys., 125, 124508, (2006)

14. W.L. Yuan, X. Yang, L. He, Y. Xue, S. Qin, and G.H. Tao, Front. Chem., 6, 1-12 (2018) 